\title{
Cosmovisão, educação e diversidade étnica para a emancipação xokleng/la klã nõ
}

Vania Konell

Professora de Artes do Instituto Federal Catarinense

Carlos Odilon da Costa

Professor da Fundação Universidade Regional de Blumenau

\section{Resumo}

Este texto relata o debate amparado nas atividades decorrentes do projeto de pesquisa financiado pela CAPES como parte do Programa Observação Educação Escolar Indígena MEC/INEP, desenvolvido junto ao grupo de Pesquisa Filosofia e Educação EDUCOGITANS instalado junto ao Programa de Mestrado em Educação da FURB. Tem como foco instigar o debate no sentido de compreender como a cosmovisão Xokleng/La klã nõ poderá, por meio da educação, contribuir para revitalizar a língua e ressignificar a cultura desse povo. Este texto incorpora como pontos referenciais a caracterização do que é cosmovisão e como ela pode atuar na educação como agente de autonomia e emancipação humana, no contexto Xokleng/La klã nõ, tendo a pedagogia freiriana com referencial que pode viabilizar o processo educativo com esses propósitos num contexto de diversidade étnica.

Palavras chave: Educação escolar indígena; Cosmovisão; Emancipação.

\begin{abstract}
This paper reports a debate supported the activities arising from a research project funded by CAPES as part of the Program Note Indigenous Education MEC/INEP, developed by the research group Philosophy and Education EDUCOGITANS installed adjacent to the Master's Program in Education FURB. Focuses provoke debate towards understanding how the worldview Xokleng / Laklanõ can, through education, to help revitalize the language and reframe the culture of these people. This text incorporates as reference points to characterize the worldview that is and how it can act as agent in education autonomy and human emancipation in the context Xokleng/Laklanõ, having reference to Freire's pedagogy that can facilitate the educational process for these purposes in the context of ethnic diversity.
\end{abstract}

Keywords: Indigenous education; Worldview; Emancipation. 


\section{Introdução}

trabalho com o povo indígena do Território Xokleng/La klã nõ
do Alto Vale do Itajaí, SC, se solidificou a partir da pesquisa de
Revitalização da Cultura e Língua desta etnia, financiado pela Coordenação de Aperfeiçoamento de Pessoal de Ensino Superior CAPES por meio do programa Educação Escolar Indígena em parceria com a Universidade Regional de Blumenau FURB junto ao grupo de pesquisa Filosofia e Educação EDUCOGITANS. Com esse programa várias atividades são oferecidas junto à comunidade indígena, sendo uma delas a formação continuada dos professores e lideranças Xokleng/La klã nõ.

Nesse sentido, o presente artigo é uma proposta de debate e reflexão em torno da perspectiva de como a cosmovisão pode se caracterizar como elemento que permeia o cotidiano das relações entre as pessoas constituintes dos povos indígenas que se apresentam em permanente contato com os não indígenas. Assim, este artigo se organiza em torno do seguinte questionamento. Como a cosmovisão Xokleng/La klã nõ poderá, por meio da educação, contribuir para revitalizar a língua e ressignificar a cultura desse povo? Essa questão nos remete à caracterização e definição do que vem a ser cosmovisão e em particular caracterizar a cosmovisão Xokleng/La klã nõ, considerando as experiências acumuladas em milhares de anos de interações das pessoas entre si e com os ambientes, considerando que eram um povo migrante e coletor e por isso, contavam com os recursos disponibilizados por seus corpos, por suas relações interpessoais e pelos ambientes, do qual recolhiam o que necessitavam para atender às suas necessidades vitais.

A forma pela qual se optou para lidar com essa proposta foi a de direcionar as ações no sentido de atuar junto aos professores numa dinâmica caracterizada como de formação permanente. Nessa perspectiva se tem Paulo Freire como autor central para orientar o desenvolvimento dessa pesquisa. Desse se buscou a perspectiva ontológica que se caracteriza como uma concepção de humano, que carrega em sua natureza a perspectiva de Ser Mais, considerando a incompletude, o inconclusão e o inacabamento 
como aspectos que identificam à humanidade dos humanos, que têm também como referencial ontológico, segundo Dussel, a vocação de ser com autonomia em permanente processo de libertação.

A dimensão ontológica como agente de compreensão do humano, se configura como ser de interação, na medida em que pode possibilitar a promoção da emancipação do sujeito, tendo como base de suas ações a cultura e a política. Essa dinâmica se mostra como processo contínuo, numa concepção que reúne inovação e conservação, que se mostra sempre atual, numa interação de novidade e conservação e num contexto sempre atual de interação entre o indígena e o não indígena, o que pode caracterizar a possibilidade de vislumbrar o humano autônomo, emancipado e por isso liberto, considerando as possibilidades objetivas e subjetivas da realidade e do contexto em que vivem conforme comunicação oral de autoria do Prof. Ernesto Jacob Keim em 2012.

\section{A cosmovisão de um povo e o trabalho no contexto da ontologia do ser social}

A palavra Emancipação é usada em geral para descrever os esforços e lutas de obtenção de direitos políticos ou de justiça social, frequentemente por um grupo especificamente privado de seus direitos ou mais genericamente na discussão de tais questões. Entre outros, Marx (2005) discorreu sobre emancipação, nesta perspectiva tem como ponto de partida o ato, que para ele, é o fundamento do ser social, ou seja, o ato do trabalho. Segundo ele, se queremos respeitar o processo real, temos que partir não de especulações ou de fantasias, mas de fatos reais, "empiricamente verificáveis", vale dizer, dos indivíduos concretos, conforma as ações e as relações que estabelecem entre si no trabalho e nas condições reais de existência.

Nessa perspectiva o primeiro ato dos homens é exatamente o ato de trabalhar. Somente assim ele pode capturar as determinações fundamentais que o caracterizam como ser social em seu processo de reprodução. De um ponto de vista ontológico, a consciência é tão importante como a realidade objetiva, de tal forma que trabalhar é, portanto, conceber antecipadamente o 
fim que se pretende alcançar e atuar sobre a natureza, para transformá-la de acordo com este objetivo.

Por outro lado, ao transformar a natureza, o homem cria, ao mesmo tempo o seu próprio ser. Tanto Marx (1989), como Lukács (2003), insistem que é por intermédio do ato do trabalho que se realiza o salto ontológico do ser natural ao ser social. A partir da análise mais rigorosa da estrutura ontológica do trabalho, pode-se perceber que o ser social é um ser radicalmente histórico e social. Isso quer dizer que não existe nada, no ser social, que seja imutável e que a totalidade deste ser é sempre o resultado dos atos humanos.

Contudo, o fato de o trabalho ser o ato originário do ser social, não significa que ele esgote a natureza deste ser. Por sua natureza, o trabalho é uma atividade que tem a possibilidade de produzir de forma cada vez mais ampla. O que significa que a complexificação sempre mais intensa é uma característica própria do ser social. Esse fator é responsável, em certa medida, pelo surgimento de problemas e de necessidades que não podem ser resolvidas ou satisfeitas diretamente pelo trabalho. A resolução destes problemas e a satisfação destas necessidades exigem a estruturação de outras dimensões específicas, como a linguagem, a ciência, a arte, a educação, o direito, a política, etc. Todas estas dimensões têm sua origem na dimensão fundante do trabalho, mas isto não significa, de modo algum, que seja por derivação direta e mecânica.

A autonomia relativa é-lhes necessária para que possam cumprir suas funções sociais. Donde se segue que, para compreender qualquer uma destas dimensões, teremos sempre que buscar as suas origens histórico-ontológicas e a função que devem cumprir na reprodução do ser social. De acordo com Marx (2009), assim como o ato fundante da emancipação política é a compra e venda de força de trabalho, o ato originário da emancipação humana deve ser necessariamente, o trabalho associado. Este ato pode ser definido, de início, como uma forma pelas quais as relações que os homens estabelecem entre si na produção econômica, mostra que as forças individuais são postas em comum e permanecem sempre sob o controle comum.

Filosofia e Educação (Online), ISSN 1984-9605 - Volume 5, Número 2, 
Como consequência, os homens detêm o controle consciente da integralidade do processo de trabalho. É isto que torna o trabalho uma atividade efetivamente livre. No entanto, é importante ressaltar que a emancipação humana não é algo inevitável. É somente uma possibilidade. Se for realizada ou não, dependerá da luta dos próprios homens.

Para outro pensador crítico, Adorno (1995), a emancipação, não se refere apenas ao indivíduo como entidade isolada, mas fundamentalmente como um ser social. Ela é pressuposto das relações igualitárias entre os humanos e se funda na formação da vontade particular de cada um, num contexto de conjunto das vontades, de tal forma como ocorre nas instituições representativas. É preciso supor, para evitar um resultado irracional, que cada um possa se servir de seu próprio entendimento. A emancipação é a formação para a autonomia, mas ela só pode ser bem sucedida se for um processo coletivo, já que na nossa sociedade a mudança individual não provoca necessariamente a mudança social, mas esta é precondição daquela.

A educação nessa dinâmica deve contribuir, portanto, para o processo de emancipação, contribuindo para criar condições em que os indivíduos, socialmente, conquistem a autonomia. Paulo Freire nesse sentido ao considerar a vocação de ser mais do humano, propunha a organização de homens e mulheres, críticos, participativos e emancipados. Essa proposta explícita em seus textos e em sua prática, enquanto educador, secretário de educação, líder, pai e esposo, entre outras atribuições sociais mostra como a dimensão de ontologia social, contribui de forma explícita ao que vem a ser uma das bases a ser considerada no debate do que caracteriza a cosmovisão de certa comunidade humana.

No processo para promover autonomia geradora de emancipação da pessoa, vimos nesse item, que na constituição da cosmovisão de um povo, é significativo que se considere a dimensão da condição humana, pautada na natureza do ser como agente, integrante e receptor do contexto social, como um elemento referencial de sua condição ontológica, a qual no conjunto dos humanos que constituem seu povo, juntamente com a cultura e os registros deixados com base na ancestralidade e na cultura, se caracteriza como os 
elementos constituintes da cosmovisão que identifica a natureza da vida desse povo.

\section{A pedagogia freiriana na diversidade étnica}

De acordo com Gadotti (2002, p. 16-18), deve-se crer que a validade universal da teoria e da práxis de Paulo Freire está ligada, sobretudo a quatro intuições originais: Por primeiro a ênfase nas condições gnosiológicas da prática educativa. Tem-se na obra de Freire a ideia de que educar é conhecer, é ler o mundo para poder transformá-lo, em uma mudança de reconhecimento a partir do respeito pelo outro, de tal forma que seu pensamento está orientado por um projeto político-pedagógico, cujo conteúdo é a libertação. Por segundo intuição se tem a defesa da educação como ato dialógico, por meio do qual Paulo Freire destaca a necessidade de uma razão dialógica comunicativa, implícita na teoria do conhecimento de Freire a qual reconhece que o ato de conhecer e de pensar, está diretamente ligado à relação com o outro de tal forma que o conhecimento precisa de expressão e comunicação e não se constitui em um ato solitário. Como terceira intuição se tem a noção da ciência aberta às necessidades populares, de tal forma que a ciência para Freire deve estar aberta às necessidades populares pelo fato de que sua posição educativa parte das pessoas (não do sistema) e são capturadas nas suas expressões, no valor da oralidade analisada por ambos, educador e educando considerando que a comunidade a que se refere é na dimensão planetária e nesse sentido Paulo Freire critica a lógica capitalista que não valorizava os prazeres gratuitos, substituindo-os por prazeres vendidos e comprados, prazeres que dão lucro, o que mostra que o capitalismo tem necessidade de substituir felicidades gratuitas, por vendidos e comprados, que são acima de tudo, necessidades do capital. E como quarta intuição se tem os planejamentos comunitários, participativos, os quais Paulo Freire reconhece que se localizam fora campo restrito da pedagogia linear, pois se caracteriza como transdisciplinar de natureza transversal, sendo que essa posição pode ser identificada desde seus primeiros escritos, quando considerou a escola muito mais do que quatro paredes, propondo que ela se organizasse em círculos de cultura que tivesse 
como cenário todo o planeta, porque a Terra deve ser assumida como o endereço cósmico de todos os povos.

Ainda de acordo com Gadotti (2002), Paulo Freire não ficou nessas quatro intuições originais. Ao longo de sua vida desenvolveu o que continuamos chamando de postura freiriana que distancia sua obra de toda conotação tecnicista. Ele não queria que sua Teoria do Conhecimento fosse reduzida a uma pura metodologia. Por isso não se pode destacar os passos de seu método, mas os passos de compreensão de sua Teoria, entendendo-os no contexto de sua epistemologia. Os passos seriam os seguintes: Ler o Mundo: Freire insistiu a vida toda nesse conceito chave do seu pensamento. O primeiro passo de sua Teoria se dá com a apropriação do conhecimento como a leitura do mundo. Destaca-se ai, a curiosidade como precondição do conhecimento. Palavras geradoras, temas geradores, complexos temáticos, codificação, decodificação, é o aprendiz que conhece. Compartilhar a leitura do mundo: Não posso saber se minha leitura está correta a não ser que a compare com a leitura do mundo de outras pessoas. Dessa forma o diálogo não é apenas uma estratégia pedagógica, mas é um critério de verdade, sendo que a veracidade surge individualmente do ponto de vista e do olhar de cada um, o que estabelece o quanto o saber individual, depende do olhar do outro, da comunicação e da intercomunicação. Só o olhar do outro pode dar veracidade ao meu olhar, o diálogo com o outro não exclui o conflito. A verdade nasce da confrontação do meu olhar com o olhar do outro.

A educação como ato de produção e de reconstrução do saber: Conhecer por isso, não é acumular conhecimentos, informações ou dados, mas implica em mudança de atitudes e estabelecimento de relações. Educar é então formar e ter consciência; é mudar de forma, é criar a forma. Daí se chega à educação como prática de liberdade (libertação) por meio a qual Paulo Freire com seu construtivismo crítico afirma que existe a politicidade no conhecimento. É o momento da problematização, da existência pessoal e da sociedade, do futuro (utopia). Dessa forma educação não é somente ciência; é arte e práxis, ação-reflexão, conscientização e projeto. A educação deve e precisa instalar esperança e nada é mais atual que esse pensamento, 
em uma época em que muitos(as) educadores(as) vivem alimentados(as) mais pelo desencanto do que pela esperança.

Nesse sentido, para entender o pensamento de Paulo Freire, deve-se saber que para ele a educação é processo sóciopolítico para a libertação, numa dinâmica que deseduca a tradicional ideologia pedagógica, ou seja, educadores para educandos mediados todos pelo mesmo objeto que procuram conhecer, não mais objetos uns dos outros, mas todos sujeitos. E quando os seres humanos se tornam sujeitos se libertam.

Nessa relação complexa, tanto educadores com educandos libertados e educandos-libertandos com educadores, pode alimentar a esperança da abolição das estruturas opressoras, porque coloca a todos para agirem como sujeitos e mediante a sua práxis, superam a desumanização. Os fundamentos em que se apoia este modelo educacional, segundo Jorge (1981, p.10) são: "a consciência crítica, o amor e o diálogo. Nesta trilogia a educação se torna uma pedagogia, capaz de construir a nova cultura, a nova política, a nova história na práxis dos educandos como sujeitos. Práxis amorosa."

Para Freire (1976), a educação e a ação cultural que está relacionada ao processo de consciência crítica como educação apresentadora de problemas, objetiva ser um instrumento de organização política do oprimido. A consciência crítica não significa confrontar-se com a realidade, assumindo uma falsa posição intelectual, que é intelectualista. A consciência crítica não pode existir fora da práxis, isto é, fora do processo ação-reflexão. Não existe consciência crítica sem compromisso histórico, portanto consciência crítica significa consciência histórica. A educação dessa forma implica o ato de conhecer entre sujeitos conhecedores e a conscientização é ao mesmo tempo uma possibilidade lógica e um processo histórico ligando teoria com práxis, numa unidade indissolúvel. As afirmações básicas da educação proposta por Freire recaem em uma epistemologia dialética para interpretar o desenvolvimento da consciência humana e seu relacionamento com a realidade. Segundo ele, as questões e os problemas principais de educação não são questões pedagógicas, ao contrário, são questões políticas.

Paulo Freire diz que a educação é prática de liberdade. Quando alguém diz que a educação é afirmação da liberdade e toma as palavras a 
sério, isto é, quando as toma por significação real, se obriga a reconhecer o fato da opressão, do mesmo modo que a luta pela libertação. De acordo com Welfort (1979, p. 5).

A visão da liberdade tem na pedagogia Freiriana uma posição de destaque. É a matriz que atribui sentido a uma prática educativa que só pode alcançar efetividade e eficácia na medida da participação livre e critica dos educandos. É um dos princípios essenciais para a estruturação do círculo de cultura. Na educação proposta por Freire, alfabetização e conscientização caminham juntas. Todo aprendizado deve encontrar-se intimamente associado à tomada de consciência da situação real vivida pelo educando (a).

A compreensão da pedagogia Freiriana em sua dimensão prática, política ou social, requer clareza ao aspecto de liberdade, que somente se adquire com a luta concreta dos seres humanos por libertar-se. Isto significa que milhões de oprimidos poderão encontrar nesta concepção educacional uma substancial ajuda ou um ponto de partida. A liberdade é um tema sempre presente em Freire, comenta Puiggrós (1999, p. 15),

A preocupação com o sentido de liberdade nos remete a Emanuel Mournier, para quem não é livre pelo mero fato de se exercitar a espontaneidade, e sim se inclina essa espontaneidade no sentido da história para inserir-se nela. Porém não se deve aderir totalmente à história que é, pois se correria o risco de não mais fazer a história que se deve ser.

Consequentemente a liberdade ocorre quando se descoloniza a mente do oprimido da presença do opressor. O ser humano moderno está dominado pelos mitos da sociedade em que vive e renuncia sua capacidade de decidir; está asfixiado no anonimato, sem esperança e sem fé, prisioneiro dos dominadores, domesticado, coisificado, por isso a pedagogia freiriana como processo e teoria educativa se caracteriza como agente importante que caracteriza a educação como elemento capaz de lidar com a diversidade étnica, para a emancipação e autonomia das pessoas e das suas respectivas organizações sociais e políticas. 


\section{Cosmovisão e educação da autonomia e emancipação humana}

De acordo com Paulo Freire (1999) a autonomia que promoverá a emancipação é como um processo que vai sendo construído na experiência de várias e inúmeras decisões que vão sendo tomadas de maneira coletiva e cooperativa de tal forma que amadurece no confronto com a liberdade dos outros. A autonomia nesse sentido é um conceito relacional, somos sempre autônomos de alguém ou de alguma coisa, sua ação se exerce sempre em um contexto de interdependência em um sistema de relações. Podemos pensar autonomia, então, como um processo de comunhão com o outro, através do diálogo que cria comunidades de seres livres e participantes. Nesse processo em construção temos o direito de decidir e decidindo é que aprendemos a fazer opções. O processo de autonomia dessa forma está centrado em experiências estimuladoras de decisões e responsabilidades, vale dizer em experiências que respeitem a liberdade e a cultura do outro. A autonomia é então resultado de um processo educacional que possibilita a libertação das pessoas.

Segundo Paulo Freire (2002), deve-se pensar que somos seres de possibilidades e não determinado, nesse sentido é importante tentar levar a cabo essa tarefa que se torna um ato de autonomia e libertação. A concepção de Educação para ele é aquela caracterizada: como um processo sóciopolítico para a libertação e autonomia, principalmente por causa de seu princípio gnosiológico do seu método, o diálogo e a comunhão. Com tais princípios e métodos, esta concepção pedagógica é contrária ao conteúdo ideológico da educação tradicional. A educação como processo libertador, deseduca a tradicional ideologia pedagógica, educadores(as) para educandos(as) e educa a educação nova no verdadeiro princípio educadores(as), com educandos(as) mediados(as) todos(as) pelo mesmo objeto que procuram conhecer, não mais como objetos uns/umas de outros/as, mas como todos(as) sujeitos, e quando homens e mulheres se tornam sujeitos eles/elas se libertam. Nesta relação raia a esperança da abolição das estruturas opressoras, porque coloca todos(as) para agirem como sujeitos mediante sua práxis, para superarem a desumanização. 
A educação como processo sociopolítico para a libertação e autonomia se assenta sobre a problematização, a qual estimula a criatividade e leva os seres humanos a uma ação e reflexão verdadeira sobre a realidade, sobre o mundo, respondendo assim, à vocação dos seres humanos que são seres autênticos quando se comprometem na procura e na transformação (FREIRE 2002, p. 52-83),

Com isso se tem que a vocação histórica e humana está precisamente na busca dinâmica de ser mais, sendo a educação da emancipação defendida neste item como o ponto de partida para a realização da vocação histórica humana. Assim, os seres humanos passam das situações limites, para o inédito viável e se tornam sujeitos e protagonistas de sua história.

Outro fundamento educacional da emancipação, segundo Paulo Freire (1999) é a incompleticidade do ser humano. Mas não somente o ser humano é considerado incompleto, mas:

Também a realidade é inconclusa em permanente devir. A incompleticidade do ser humano, porém, não deve ser apenas um dado a mais sobre o qual eles sabem. Não a educação para libertação e autonomia os leva a tomarem consciência desta incompleticidade criticamente e, assim conscientes, partirem para a busca permanente, no mundo e com o mundo no qual eles/elas estão. $\mathrm{O}$ caráter inacabado do ser humano e da realidade fará que a educação também seja uma atividade continua, assim a educação é constantemente refeita pela práxis, parta ser deve chegar a ser. a educação problematizadora que conduz para a libertação e autonomia, não aceita um presente bem conduzido, nem um futuro pré determinado, enraíza-se no presente dinâmico e chega a ser revolucionária (1999, p. 55-59).

Os fundamentos em que se apóia a Educação da emancipação defendida por Paulo Freire (2002, p. 165-184) são, a consciência crítica, o diálogo, o amor e a organização e o ponto de partida da educação como processo de libertação e autonomia, nas palavras dele é o ser humano oprimido ao considerar que... 
A história está nas mãos dos seres humanos. A história como algo inelutável foi um mito criado pelas estruturas opressoras para, de um lado, satisfazerem seus desejos e ambições, especialmente o ter mais, e, de outro, para cortar aos oprimidos(as) toda forma de rebeldia a esta história trágica que desabava sobre eles. A história é o tempo dos acontecimentos humanos e está feita pelos seres humanos ao mesmo tempo que eles/elas se vão fazendo nela. O diálogo é o instrumento com que se realizará o processo de humanização, pois, o diálogo é o mais humano meio que os seres humanos dispõe para se encontrarem, se relacionarem, e como a educação para a libertação e autonomia é profundamente humana, opção pelos (as) oprimidos (as), ela não poderá de se furtar ao instrumento essencial libertador. O diálogo é a palavra do ser humano existencializado, é a palavra ação, é a palavra quefazer. E já que são os quefazeres humanos a práxis da libertação, a educação como processo social para a libertação e autonomia tem, na palavra, a sua práxis. O diálogo é a práxis libertadora. O diálogo é assim o sinal verde da esperança (Freire 1980, p. 57-87).

Nesse sentido pode-se pensar o diálogo como umas das características vitais da interculturalidade. Em um mundo cada vez mais globalizado em sua economia, comunicação e cultura, as relações sociais tornam-se mais transnacionais e no plano cultural, existe o desafio da hibridação e da diversidade e por sua vez há também a necessidade do respeito ao reconhecimento à diferença. Juntamente com a defesa e reconhecimento das múltiplas identidades constituintes da realidade e contexto social, tratados pela multicultualidade, surge à necessidade de abertura ao outro, na qual a reciprocidade manifesta como interculturalidade, possibilita que tal contexto altamente complexo e dinâmico inerente aos movimentos sociais e grupos culturais, requerem novas orientações epistemológicas no campo da formação de professores e da sociedade.

No debate entre a visão de uma única cultura (monoculturalidade), versus a visão de diferentes culturas (multiculturalidade), a multiculturalidade ao enfatizar a historicidade e o relativismo inerentes a construção das identidades culturais, permite pensar alternativas para as minorias, mas, também pode justificar a fragmentação ou criação de 
espaços exclusivos de culturas reprodutoras de desigualdades e descriminações. Para além da discussão mono e multi, construiu-se a perspectiva intercultural, que nas palavras de Fleuri (1998) seria:

O interculturalismo propõe uma dimensão dinâmica de contato, interação, troca, na qual a diversidade conta como interlocutor ativo. O termo intercultura, aponta para um projeto que, no plano educacional, pretende intervir nas mudanças induzidas pelo contato com as diversidades, de modo a promover atitudes abertas ao confronto e conduzir os processos aculturadores a uma integração entre culturas que não colonializem as minorias.

Com essa posição de criticidade do contexto social e planetário que incorpora inúmeras e complexas realidades se tem, no contexto de espaço e tempo as relações que constituem a cosmovisão de cada povo, a qual como vimos se constitui como argumento e sentido para debater a natureza e o sentido do que vem a ser Educação da Autonomia e Emancipação Humana como processo que deve se pautar em algo com propósito direto de se caracterizar como de natureza descolonizadora.

\section{Educação e cosmovisão no contesto xokleng/laklãnõ}

Ao trabalhar com a etnia Xokleng/Laklãnõ, após os primeiros encontros na Terra Indígena Laklãnõ no Alto Vale do Itajaí em Santa Catarina, percebeuse que a vertente pedagógica presente nas escolas indígenas ali existentes, apesar de terem como docentes apenas professores indígenas, atuava regida com base numa concepção ditada por uma ótica emancipacionista que retratava muitas vezes a diversidade enquanto somente um déficit a ser superado, adotando uma postura que objetivava promover a ascensão das classes subalternas à cultura oficial.

Com a possibilidade de se estimular a comunidade indígena a desencadear, em suas atividades educativas, uma abordagem intercultural e de natureza pós-colonial, se adotou postura de estimulação e esclarecimento da possibilidade de realização nas escolas indígenas de um processo de 
natureza de libertação que poderia levar à formação de nova mentalidade que brotasse da comunidade e que fosse pela comunidade desenvolvida como algo próprio e particular dela.

Assim a educação que a comunidade indígena passou a considerar como relevante tinha a cosmovisão como uma condição própria de seu grupo social e étnico composto por aspectos que se manifestam na forma como alguns povos percebem o mundo, pela forma como interagem com os demais, pela forma como se comunicam e também sobre o que comem, bem como com relação às crenças e valores, que professam pautadas na ancestralidade como história e sabedoria. Por isso ao trabalhar e se relacionar com o cotidiano de suas vidas, as pessoas pertencentes ao povo indígena Xokleng/Laklãnõ percebeu-se que a visão de mundo e o propósito de vida se encontram na cosmovisão de sua comunidade. Esse reconhecimento possibilita que tenham maior capacidade de interagir com as comunidades de diferentes etnias que ficam à sua volta.

Como referencial para o debate é interessante colocar que Patrícia Pérez Morales (2008, p. 22) apresenta a cosmovisão como...

A forma de pensar-agir, de viver no mundo, que tem cada cultura, a qual é construída através do espaço-tempo, e que se renova e atualiza permanentemente por meio de suas práticas, de seus princípios, de sua cultura, de sua educação; isto é, da forma em como uma cultura pensa o mundo e vive nele, como constrói suas relações com os outros, com a natureza, com seus ancestrais, etc..., portanto, é uma forma particular e característica que tem cada cultura de compreender o mundo em que vive.

Assim, a cosmovisão e a identidade indígena buscam argumentos para a reflexão acumulada sobre o reconhecimento ontológico que encontra no princípio da ancestralidade a base da tradição. O povo Xokleng/Laklãnõ busca, através da cosmovisão, revitalizar sua cultura e língua, priorizando a identidade através da educação escolar indígena. Para Eduardo OLIVEIRA: “A identidade se constrói com relação à alteridade. Com aquilo que não sou eu. É diante da diferença do outro que a minha diferença aparece" (2006, p. 84). De acordo com o autor mencionado a tradição cria identidades, pois ela 
é o manancial dos valores civilizatórios e dos princípios éticos. Segundo Oliveira

A tradição não existe sem a ancestralidade. A ancestralidade, por sua vez, não é a afirmação do eu, heróico, narcisista; na ancestralidade o que conta é a história de um povo, o arsenal simbólico adquirido por este durante o percurso do tempo. Quem conta a história do eu é sua tradição. A história do eu está vinculada a história de seus ancestrais. O que faz parte de um todo e é importante justamente na medida em que compõe esse todo, e não o contrário. É por isso que podemos que sem ancestralidade não há identidade. A identidade é encontrada na tradição e não no olhar narcisista. A construção da tradição é coletiva. Não importa se esta construção é cultural, isto é, que ela sofre modificações ao longo da história. O que importa é que ela é capaz de identificar os elementos que congregam e caracterizam uma certa visão de mundo (2006, p. 120).

Portanto a cosmovisão é a consciência de mundo construída a partir da ancestralidade e isto se torna importante à medida que é preciso se conhecer para conhecer o outro. A cosmovisão desse povo é extremamente particular e complexa, pois se encontra no modo como eles pensam como agem ou interagem. A ancestralidade se caracteriza como um referencial da identidade do povo indígena, como cita Patricia Pérez Morales ao dizer que ela:

Representa a origem comum, seu caminhar histórico como povo, que os unifica em sua cultura. Sua presença é atualizada por meio de seus antepassados, de seus conhecimentos e cotidianidade, é uma vivência permanente através dos rituais, celebrações e no dia a dia, seus ancestrais estão sempre presentes na vida da comunidade, pertencem a ela. Então, viver o passado no presente como uma abertura ao depois, é o sentido da ancestralidade, uma ancestralidade que carrega vivências e significados, é uma procura no profundo do tempo-espaço que dá sentido à vida do aqui e do agora (2008, p. 49).

O povo Xokleng/Laklãnõ tem sua cosmovisão caracterizada pela sensibilização e sentimento, o que diferencia do contexto civilizatório não 
indígena que se baseia no sentido e na racionalidade. O povo indígena Laklãnõ reconhece o valor da família, das pessoas da comunidade, seja da criança mais prematura até a pessoa de mais idade, todos são vistos com um olhar que retrata o respeito. Quando muitas vezes os professores levaram seus filhos juntos para alguma atividade relacionada ao programa de pesquisa base desse texto, foi possível perceber como era diferente a maneira como os indígenas tratavam suas crianças. Em nenhum momento percebeu-se alguém gritando com as crianças ou incomodados com o que elas estavam fazendo. As crianças não choraram e nem expressaram comportamento de rebeldia, apenas manifestaram momentos de curiosidade. Pareciam estar conscientes das suas atitudes, como se já tivessem maturidade para estar participando e opinando.

Foi possível perceber também que a cosmovisão Xokleng/Laklãnõ, promove o respeito pela dignidade dos anciãos e dos pais. Isto ficou cada vez mais evidente, principalmente quando no curso, para construirmos um debate em torno da infância como temporalidade humana encontrada na escola e na sociedade indígena, no momento das opiniões em torno do assunto uma professora indígena se manifesta dizendo, que para seu povo "a infância termina com o casamento", e algumas outras indígenas, concordam, mas com ressalvas, ao relatar no grupo que o conceito de infância também passa pelo crivo individual, ou seja, cada pai ou mãe percebe seu filho como um a criança ou um adulto, e uma delas deu exemplo em que "Seu filho que estava servindo na base aérea de Florianópolis retornou para sua casa com 21 anos e na noite do retorno, retomou hábitos próprios da época em que era criança”, ela continuou seu relato e afirmou que mesmo após o casamento ele "continuou com esse hábito a cada vez que retornava ao lar materno". Outro exemplo seria do indígena de 29 anos que estava prestes a casar e em uma discussão com seu pai na casa paterna na frente de sua futura esposa, teve que segundo ele "deixar que seu pai o repreendesse de forma severa" e dizer alto e em bom tom, que "quem mandava naquela casa era ele e ainda era seu pai". Outros depoimentos foram somados juntamente com estes, que de certa forma, levou-nos a refletir sobre o grau de complexidade dessas "sociedades" indígenas e também o grau de dificuldades em tentar 
compreende-las, o que ficou evidente em nosso debate e reflexão é que ao se deparar com diferentes concepções de vida e de modo de produzir as necessidades vitais, devem estar presentes os elementos diálogo e compreensão, o que ao ver dos pesquisadores podemos encontrar em uma abordagem intercultural baseada na amorosidade, diálogo e organização proposto nos escritos de Paulo Freire.

Portanto são aspectos particulares que identificam os princípios familiares e sociais desse povo, que busca através da cosmovisão a revitalização da cultura e língua Xokleng/Laklãnõ. A educação emancipatória intercultural pautada nos estudos e escritos de Paulo Freire busca compreender o ser humano e como ele interage com o mundo, num processo que gera autonomia e libertação.

\section{Considerações finais}

Considerando o ser indígena Xokleng/Laklãnõ, por sua parte, como sendo incompleto, buscando ser mais e, por outra, estando a realidade em permanente devir, segue-se que a busca feita por ele tem de ser permanentemente por causa de sua incompleticidade e pelo permanente devir da realidade, assim quanto mais o ser indígena Laklãnõ busca, mais deverá buscar, os achados de sua busca lhe exigirão novas buscas. Se a busca é permanente, a educação emancipatória intercultural proposta por Freire que parte das buscas dos seres humanos para serem mais e da realidade em permanente devir, não tem um momento absoluto no qual o ser humano não precise se educar mais nem se conhecer mais.

Com base nos princípios de educação emancipatória intercultural, podemos dizer que a educação indígena parte de uma perspectiva que valoriza a identidade e a cosmovisão. Portanto a educação escolar indígena precisa estar pautada na reflexão, no diálogo e na compreensão para buscar aspectos pedagógicos que possam identificar questões objetivas e subjetivas desse povo. Neste contexto é importante destacar que as particularidades do povo Xokleng/Laklãnõ devem ser consideradas como fundamentais num processo de construção da identidade ontológica para revitalizar a cultura e a língua. 
Com uma educação pautada nos princípios da cosmovisão, ontologia e cultura, o povo indígena Xokleng/Laklãnõ busca o reconhecimento da sua identidade. Sendo assim a concepção de formação do professor e das lideranças passa por um entendimento intercultural, apesar das dificuldades existentes, busca na escola a revitalização da sua cultura, através dos ensinamentos da sua língua, história e dos costumes do seu povo.

\section{Referências}

ADORNO, T. Educação e Emancipação. Rio de Janeiro: Paz e Terra, 1995, 190 p.

FLEURI, Reinaldo Matias. Intercultura e Movimentos Sociais. Florianópolis: Mover, 1998, 212 p.

FREIRE, Paulo. Pedagogia do oprimido. 34. ed. Rio de Janeiro: Paz e Terra, 2002, $184 \mathrm{p}$.

FREIRE, Paulo. Ação cultural para liberdade e outros escritos. Rio de Janeiro: Paz e Terra, 1976, $149 \mathrm{p}$.

FREIRE, Paulo. Conscientizạacão. São Paulo: Moraes, 1980, 93 p.

FREIRE, Paulo. Educação como prática da liberdade. 9. ed. Rio de Janeiro: Paz e Terra, 1979, $150 \mathrm{p}$.

FREIRE, Paulo. Pedagogia da autonomia. Saberes necessários à prática educativa. Rio de Janeiro: Paz e Terra, 1999, 165 p.

GADOTTI, Moacir. Aprender, ensinar. Um olhar sobre Paulo Freire.

Abceducatio a Revista da Educação. São Paulo: Criart, ano 3, n. 14, 2002, 42 p.

JORGE, J. Simões. Educação crítica e seu método. São Paulo: Loyola, 1981, 110 p.

LUKÁCS, G. Por uma Ontologia do Ser Social. São Paulo: Boitempo, 2003, 440 p.

MARX, Karl. Manuscritos Econômico-Filosóficos. São Paulo: Escala 1999, 404 p.

MARX, Karl. Crítica da Filosofia do Direito em Hegel. São Paulo: Boitempo , 2005, $95 \mathrm{p}$.

MARX, Karl. Sobre a Questão Judaica. São Paulo: Boitempo, 2009, 89 p.

MORALES, Patrícia Pérez. Espaço-tempo e ancestralidade na educação ameríndia: desdobramentos de Paulo Freire na provincia de Chimborazo, Equador. 2008, 240 p.

OLIVEIRA, Eduardo. Cosmovisão Africana no Brasil: elementos uma filosofia afrodescendente. Curitiba: Editora Gráfica Popular, 2006, 188 p.

Filosofia e Educação (Online), ISSN 1984-9605 - Volume 5, Número 2,

Outubro de 2013 
PUIGGRÓS, Adriana. Paulo Freire do ponto de vista da interdisciplinaridade. In: WELFORT, Francisco C. Educação e política. In: FREIRE, Paulo.

Educaşão como prática da liberdade. Rio de Janeiro: Paz e Terra, 1979, 150 p. 